\title{
The Acute Management of Facial Fractures
}

\author{
Anne-Frederique Chouinard ${ }^{1} \cdot$ Maria J. Troulis ${ }^{1} \cdot$ Edward T. Lahey ${ }^{1}$
}

Published online: 15 April 2016

(C) Springer International Publishing AG 2016

\begin{abstract}
Facial fractures lead to functional and esthetical deficits if not treated properly. Appropriate acute management of facial fractures must be based on prompt and thorough evaluation. Some fractures are best treated in a delayed fashion; others represent real emergencies and need to be treated within $24 \mathrm{~h}$ of trauma. Different types of reduction and fixation exist depending on the age of the patient, the location and type of fracture, and on the surgeon's preference.
\end{abstract}

Keywords Facial fracture $\cdot$ Fractures $\cdot$ Facial reconstruction . Facial trauma

\section{Introduction}

Facial fractures occur most commonly in males in the third decade of life [1]. The most frequent causes of facial fractures are motor vehicle collision (MVC), interpersonal violence (IPV), falls, and sports-related accidents. Their respective

This article is part of the Topical Collection on Fracture Considerations for the General Surgeon

Anne-Frederique Chouinard

achouinard1@partners.org

Maria J. Troulis

mtroulis@partners.org

Edward T. Lahey

elahey@partners.org

1 Department of Oral Maxillofacial Surgery, Massachusetts General Hospital, Harvard School of Dental Medicine, 55 Fruit Street, Warren 1201, Boston, MA 02114, USA prevalence is geographically dependent. MVCs are the most important mechanism worldwide. More recently, in North America and Europe, an increase in IPV is noted [2]. Nasal fractures are the most frequent, followed by dentoalveolar and mandibular fractures, midface and orbital floor fractures, and then frontal sinus [3].

Concomitant injuries occur in about $16-35 \%$ of cases with maxillofacial injuries [4-6]. Depending on the population, orthopedic injuries represent about $50-64 \%$ of these associated injuries with head injuries representing about $16-54 \%$ of them; next come after the cutaneous, the cervical spine, and the pulmonary injuries [4-8]. Patients with multiple facial fractures are more likely to have a concomitant head injury (66 to $89 \%$ ) compared to patients with a single facial fracture [9].

In maxillofacial trauma, airway assessment represents a key part of the clinical examination. Upper airway obstruction can be secondary to hemorrhage, edema, displaced or comminuted fractures, and foreign bodies such as dentures. Securing the airway needs to be addressed prior to any other evaluation/ treatment as per ATLS guidelines. Clinical examination and computed tomography imaging are the gold standards in the diagnosis, planning, and management of maxillofacial fractures [10].

\section{Roles of Antibiotics}

The use of antibiotics in maxillofacial fractures remains controversial. When considering antibiotic therapy, the risks factors for infection need to be assessed. There are no questions about the necessity of antibiotics during the perioperative time $[11,12 \cdot]$ and in the presence of an infected wound [13]. The practice of protracted courses of pre- and postoperative antibiotics despite the lack of supporting evidence persists. This 
practice should be rethought given the increase in antibiotic resistance and antibiotic-associated complications such as Clostridium difficile colitis. Cephazolin and clindamycin are the two antibiotics more frequently used in the perioperative period $[12 \cdot]$.

In general, facial fractures are at low risk of postoperative infection. The midface as well as the condylar head of the mandible are at low risk of postoperative infection as compared to the angle, body, and symphysis of the mandible (tooth-bearing segments) [11, 14].

A distinction to be made is "open" versus "closed" fracture. Open jaw (maxilla and mandible) fractures are contaminated by saliva through the sulcus of the teeth or mucosal lacerations. These fractures may benefit from antibiotic coverage to prevent postoperative infection [13]. A systematic review conducted by Andreasen showed a lower infection rate for mandibular fractures that were put on a short-term antibiotic regimen (less than $48 \mathrm{~h}$ peri- and postoperatively) [14]. Longer postoperative antibiotic therapy has not been proven beneficial and may lead to drug complications [15-17].

For midface fractures, as the sinuses are thought to be a source of contamination, some surgeons prescribe prophylactic antibiotics to prevent orbital cellulitis and wound infection. To date, no proven benefits exist in the literature $[12 \bullet, 18]$. Sinus precautions such as no nose blowing, sneezing with an open mouth, and avoidance of straws may prove to be most important.

\section{Acute Versus Delayed Reconstruction}

Acute treatment is done within $72 \mathrm{~h}$ after trauma. Immediate reconstruction is done within 2 weeks and delayed reconstruction is considered at any time after 2 weeks. The timing for repair relies mostly on surgeon's preference, hospital resources, and the clinical presentation $[19,20]$.

Acute reconstruction is indicated in orbital fractures with muscle entrapment to prevent muscle atrophy. Airway compromise and hemorrhage are also indications for acute reduction. In mandibular open fractures, delaying repair may increase bacterial load and osseous devascularization, so early immobilization is recommended [21]. In other fractures such as zygomatic fractures, a short delay in the reconstruction may be advantageous; edema of the overlying soft tissue may minimize the appearance of the defect [22].

Following bone consolidation of non-reduced facial fractures, reconstruction becomes a surgical challenge requiring use of osteotomies and/or onlay grafts. Primary repair usually offers best functional recovery as well to "easier" repair (Fig. 1).

\section{Mandible}

\section{Clinical Signs and Symptoms}

The most frequent clinical sign associated with mandibular fractures is malocclusion. Mucosal lacerations, bleeding from the tooth sulcus at the fracture location, and gingival ecchymosis are signs of a fracture that should alert the clinician when there is no apparent malocclusion. Dentoalveolar trauma is often observed with mandibular fractures. Other signs include trismus, pain with mastication, floor of the mouth hematoma, facial asymmetry, and paresthesia of the third trigeminal division [23].

\section{Fracture Description}

Mandibular fractures are the second most frequent fracture of the maxillofacial skeleton after nasal fractures [24]. Lowvelocity blunt injuries are the most common cause of mandibular fractures [25]. Angle fractures are the most frequent (27\%) followed by the symphysis $(21 \%)$, condyle/ subcondyle (18\%), and body (16\%) fractures. Single site fracture and multiple site fractures are equally distributed among all the mandibular fractures [25].

Mandibular fractures can be classified as (1) open versus closed, (2) displaced versus nondisplaced, (3) simple versus complex versus greenstick, and (4) anatomically by site or favorable versus unfavorable. Mandibular fractures may not have skin/mucosal openings, but if the fracture is through periodontal ligament, it is considered an open fracture. The masseter, pterygoid, and suprahyoid muscles attach to the mandible. Depending on the location and the angulation of the fracture, these muscles, by their action, can displace unfavorably the bony fragments or they can help keep the fragments aligned. This aspect has to be considered when choosing the appropriate reduction technique. In bilateral body fractures of atrophic mandibles, the muscle pull can lead to airway collapse secondary to displacement of fragments (the socalled bucket handle fracture).

\section{Indications for Reduction}

General goals of reduction are to restore the proper function such as chewing and speaking, to stabilize and correct the occlusion, to obtain pain-free mandibular range of motion, to restore the premorbid mandibular contour, and to offer enough stability to ensure bony union and decrease infection risk [26].

\section{Treatment Options}

Mandibular fractures are most commonly treated by (1) closed reduction with maxillomandibular fixation; (2) observation 


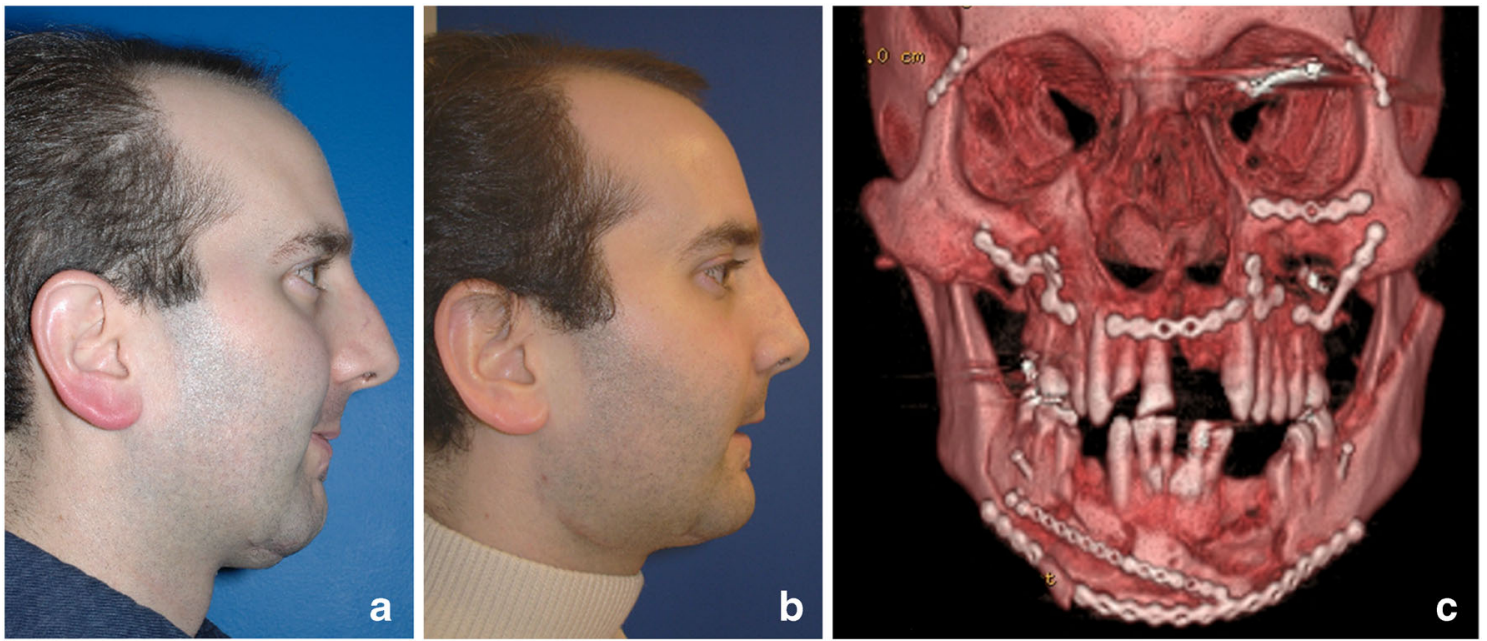

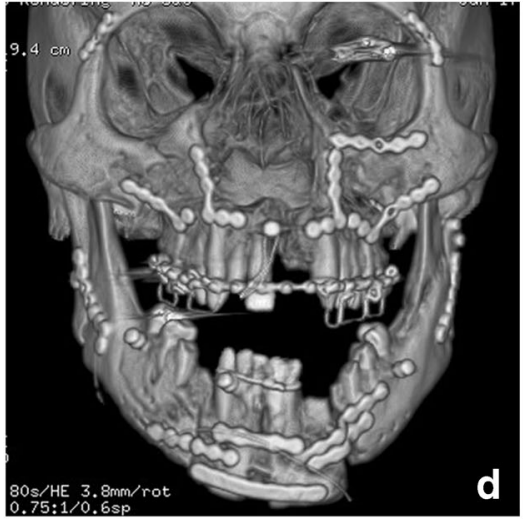
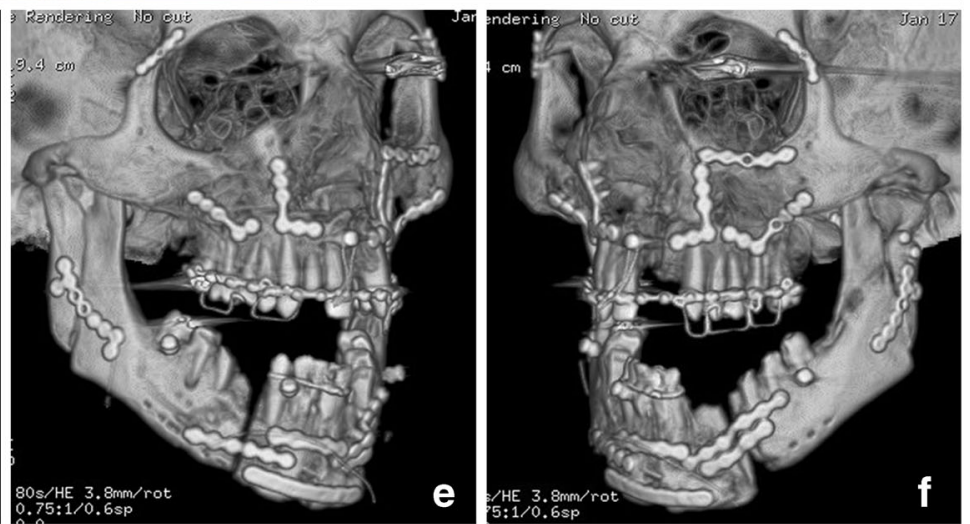

Fig. 1 Patient had inadequate primary reduction. Revision surgery with planned osteotomies was necessary to correct his facial appearance. a Preoperative lateral view showing midface and mandibular anterior-posterior deficiency. b Post-operative lateral view showing improvement of facial profile. c Pre-operative frontal view 3D reconstruction scan showing midface and mandibular widening as a result of inappropriate reduction. d Post-operative frontal view demonstrating narrowing of facial skeleton. e, f Post-operative lateral views of revision surgery showing the different necessary osteotomies with diet/activity modification, and (3) open reduction with internal fixation. Choice selection between these techniques depends on surgeon preference, anatomical characteristics, types of fracture, or patient request/specificity.

Closed reduction is most frequently indicated in grossly comminuted fractures, condylar head fracture to preserve blood supply to the fragments, and subcondylar fractures. Most other mandibular fractures can be treated in this fashion as long as enough stable teeth are present on both sides of the fracture. Some nondisplaced or incomplete fracture can be treated with blenderized diet. Regular follow-ups are mandatory to make sure the fracture is stable. Open reduction with internal fixation is indicated in patients in which maxillomandibular fixation is contraindicated, in severely atrophic edentulous cases and in fractures not adequately reduced with closed reduction (Fig. 2). Specific indications for open reduction of subcondylar fractures have been described by Zyde and Kent [27] and more recently by Ellis [26]. They are displacement of the condyle into the middle cranial fossa or lateral extracapsular displacement, impossibility of obtaining proper occlusion with closed technique or condylar fractures associated with midface fractures. For subcondylar fractures, minimally invasive open reduction technique is possible with the endoscopic approach [28-31] (Fig. 3).

\section{Reduction/Immobilization Techniques}

Dental occlusion serves as a landmark to guide fracture treatment. With closed reduction, occlusion is reestablished and maintained with maxillomandibular fixation. Immobilization is maintained for an average period of 4 to 8 weeks, usually with arch bars. Closed reduction can be obtained with local anesthesia but open reduction usually requires a general anesthesia. In open reduction, maxillomandibular fixation is used as an aid for appropriate anatomical reduction of bony segments. Depending on the type of internal fixation used, usually titanium plates and screws (wire internal 

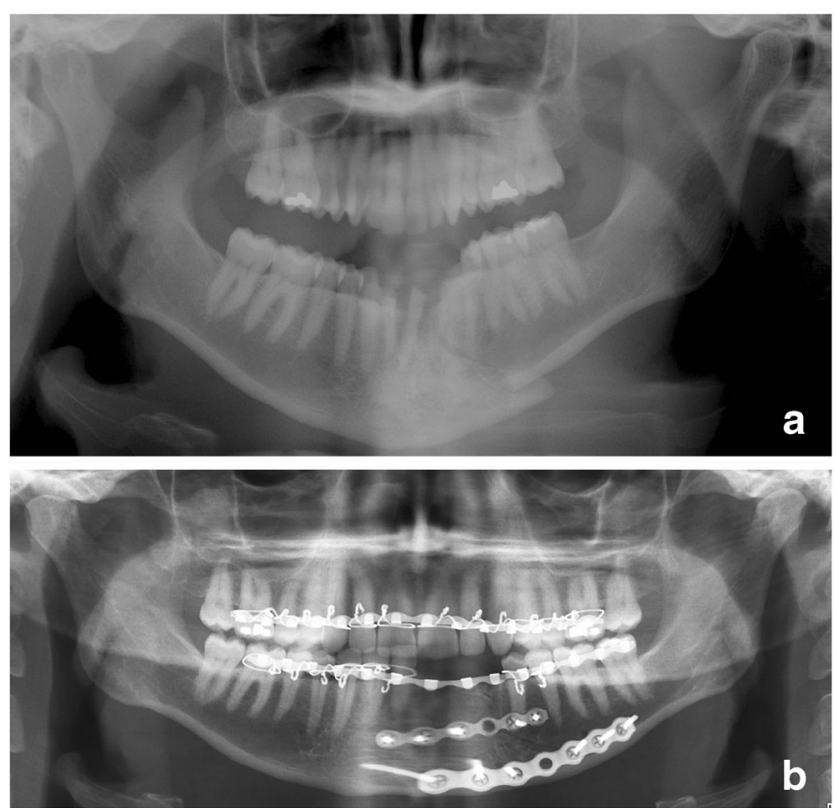

Fig. 2 a Panoramic radiograph of left parasymphysis mandibular fracture associated with dentoalveolar trauma. b Post-operative panoramic radiograph of the same patient after open reduction with internal fixation fixation has been phased out), intermaxillary fixation may be removed following fixation.

\section{Orbital Fractures}

\section{Clinical Signs and Symptoms}

Clinical signs of orbital fractures are periorbital edema and ecchymosis, conjunctival hemorrhage, limited extraocular movements, diplopia, and paresthesia of the infraorbital nerve distribution. Once most of the edema has resolved, enophthalmos and vertical dystopia can be seen when a significant bone defect is present. Immediately following orbital trauma without entrapment, diplopia is most likely due to edema or muscle contusion. If the double vision persists for more than 2 weeks, it is more likely secondary to the orbital wall fracture and the new globe position. In trapdoor fracture with muscle entrapment, limitations in the extraocular movements (vertical restriction) with significant pain with eye movement are the most common clinical sign. In rare orbital
Fig. 3 a Panoramic radiograph of bilateral subcondylar fracture, left side fracture pointed with arrow. b Intra-operative endoscopic view of the same patient during open reduction and internal fixation of left subcondylar fracture. c Postoperative panoramic radiograph of the same patient after endoscopically assisted open reduction with internal fixation of left subcondylar fracture
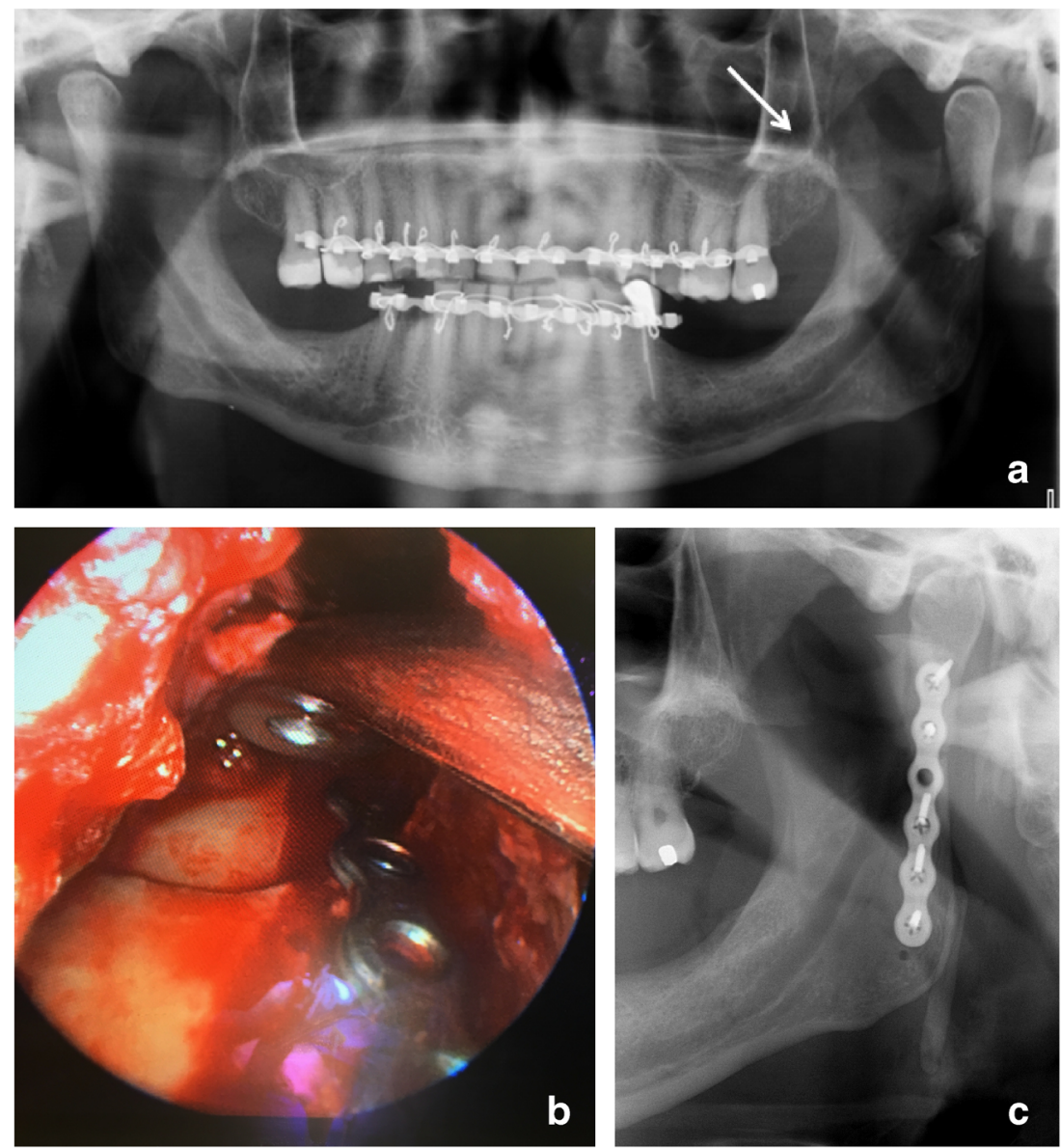
entrapment cases, patients can become bradycardic and nauseous secondary to oculocardiac reflex.

\section{Fracture Description}

Orbital wall fractures occur from raised intraorbital pressure and are theorized to be a protective mechanism preventing compression of the globe during trauma. The most commonly affected walls are the thinnest ones, the floor and the medial wall. There are two types of orbital floor fractures: the orbital blowout fracture which leaves a defect due to bone displacement or a trapdoor fracture where the fractured segments regain their original position, trapping some of the orbital content, such as fat or muscle. Muscle entrapment represents a surgical emergency and requires prompt treatment. This type of fracture occurs more frequently in children because of the more elastic property of bones in this population.

\section{Indications for Reduction}

Acute treatment is indicated in cases of trapdoor fractures with symptomatic diplopia and incarcerated muscle to prevent muscle necrosis. In the presence of a nonresolving oculocardiac reflex, acute repair is also mandatory. The presence of enophthalmos greater than $2 \mathrm{~mm}$ and/or a radiological defect size greater than $50 \%$ of the floor justify an acute reconstruction in blowout fracture $[32,33 \bullet]$. Orbital volume can be evaluated with a CT scan. A volume change of over $8 \%$ (around $2 \mathrm{~mL}$ ) usually implies a poor outcome. One milliliter of increased orbital volume results in $1 \mathrm{~mm}$ of enophthalmos [34].

Reconstruction is normally within 2 weeks after trauma. Indications are persistent symptomatic diplopia, delayed enophthalmos greater than $2 \mathrm{~mm}$ in the anteroposterior direction, and progressive infraorbital nerve hyperesthesia [32]. When no functional or esthetic deficits are present 2 weeks after the injury, observation is an appropriate fracture management [32].

\section{Reduction Techniques}

Different approaches through skin or conjunctiva are possible to access the orbit. More recently, endoscopic approach via the maxillary sinus has been described $[35,36]$. Because orbital bone walls are very thin, most of the time, implant reconstruction is more appropriate than simple reduction of the fracture. Different kinds of implants are available such as titanium mesh, porous polyethylene implant, silicone sheeting, autogenous cartilage, and bone [33•]. Implant choice relies on patient characteristics and surgeon preferences [37]. The goals are to support the globe and to recreate adequate orbit volume.

\section{Midface Fractures}

\section{Clinical Signs}

Midface fractures include the orbital fractures as previously described, the Lefort fractures, the zygomatic complex fractures, the nasal fractures, and the nasoorbito-ethmoidal (NOE) fractures. Edema and facial asymmetry are the most common clinical signs of midface fractures. Lefort 1 fractures most commonly present with an anterior open bite. Mandibular maximal opening can be limited in cases where the zygomatic arch is depressed and is impinging the rotational movement of the coronoid process. Nasal deviation, septal hematoma, telecanthus, and epistaxis are signs of nasal complex fractures. Infraorbital nerve paresthesia is frequent with all midface fractures [23].

\section{Zygomaticomaxillary Complex}

\section{Fracture Description}

The zygoma articulates with maxillary, frontal, sphenoidal, and temporal bones via the zygomatic arch creating the zygomaticomaxillary complex (ZMC). Because of its geometry, ZMC displacement tends to be in a pivoting fashion creating flattening and depression of the cheekbone or increasing projection of the lateral orbital rim.

\section{Indications for Reduction}

Indications for reduction of ZMC fractures alone are cosmetics except in cases where there is a mechanical blockage limiting mouth opening between the zygomatic arch which is medially displaced and the coronoid process.

\section{Reduction Techniques}

ZMC fractures can be treated with open or closed reduction depending on the degree of displacement and on the mobility post-reduction. ZMC can be fixed at 1, 2, or 3 points (fronto-zygomatic suture, inferior orbital rim, and zygomaticomaxillary buttress) with osteosynthesis plates (Fig. 4). The zygomaticosphenoid suture actually provides the best indication for reduction but is rarely a site of fixation. A combination of approaches allows to expose the zygomatic bone (i.e., intra-oral, sub- and supraorbital) [38]. 

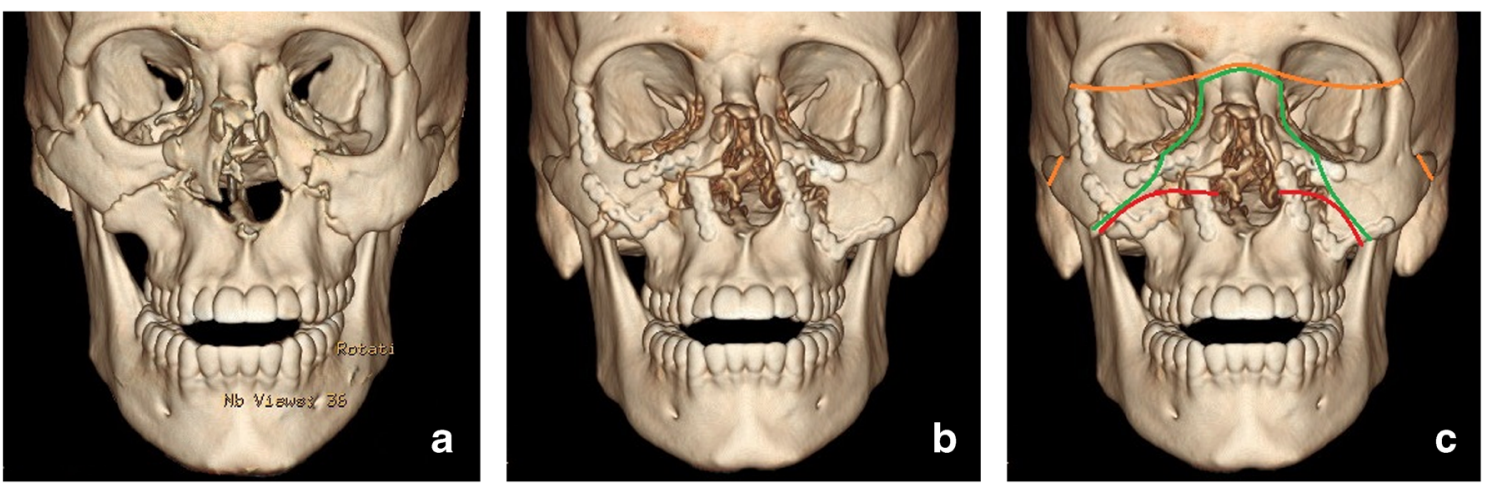

Fig. 4 a Pre-operative 3D reconstruction scan of bilateral Lefort 1 fracture with bilateral zygomatic and orbital floor fractures. b Post-operative 3D reconstruction scan of the same patient after open reduction with internal fixation. c Same patient with schematic representation of Lefort fracture classification. Type I corresponds to a dissociation between the

\section{Lefort Fractures}

\section{Fracture Description}

Lefort fractures are classified depending on the pattern between the maxilla and the rest of the craniofacial skeleton (Fig. 4c).

\section{Indications for Reduction}

The main goal for reduction is to reestablish the premorbid occlusion and facial projection and to prevent facial lengthening [39].

\section{Reduction Techniques}

In most cases, Lefort fractures need to be treated with open reduction with internal fixation regardless of type. In few cases when the patient is edentulous, the fracture can be treated with observational approach. Furthermore, in edentulous patients, osteosynthesis plates can be difficult due to the atrophic nature of the maxillary bones.

Open reduction is accomplished via intra-oral approach for Lefort I. In cases of Lefort II, different surgical approaches are necessary to access the different fracture lines. Many are the same as those used for the treatment of ZMC fractures. Coronal incision is the best way to address the upper portion of a Lefort III fracture. An intra-oral incision is still usually necessary in Lefort II and III fractures.

\section{Nasal Complex Fractures}

\section{Fracture Description}

Nasal complex fracture can be as simple as isolated nasal bone fracture to NOE fractures with avulsion of the medial canthal maxilla and the rest of the face (red line), type II also known as the pyramidal fracture represents a dissociation between the central portion of the midface and the rest of the face (green line), and type III represents a craniofacial dissociation III (orange line)

ligament. NOE fractures consist of comminution of medial orbital walls, nasal, and lacrimal bones with or without avulsion of the medial canthal ligament. There are three types of NOE fractures (Fig. 5).

\section{Indication for Reduction}

Nasal and septal deviations are primary indications for nasal fracture reduction. Telecanthus, medial canthal ligament avulsion, and NOE complex impaction are indication for reduction of NOE fractures [39].

\section{Reduction Techniques}

Closed reduction of isolated nasal fracture is usually the ideal treatment [40]. It can be done either under general or local

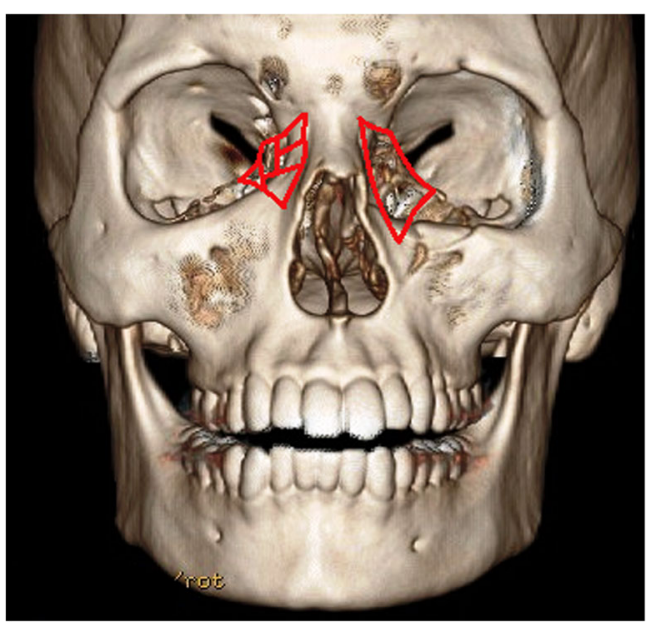

Fig. 5 Different types of NOE fractures. Type I represented on patient left side: a single-segment central fragment, Type II represented on patient right side: comminuted fracture without avulsion of the medial canthal ligament, Type III comminuted fracture with avulsion of the medial canthal ligament 
anesthesia with no significant difference between the two techniques [41]. Open reduction with internal fixation is the standard treatment for NOE fractures [39]. Adequate reduction of the maxillary-frontal buttress and repositioning of the medial orbital wall is treatment key to correct the telecanthus often seen with these fractures. When necessary, reinsertion of the medial canthal ligament is done with suture or wire.

\section{Frontal Sinus}

\section{Clinical Signs}

Common signs are frontal and orbital ecchymosis, skin laceration, swelling, subcutaneous emphysema, and frontal hypoesthesia [42]. Frontal depression following anterior table fracture can be the more noticeable signs once the swelling has gone down. Fracture of the posterior table may cause cerebrospinal fluid leaks. Mucocele and mucopyocele can be delayed signs of frontal sinus fractures. On imaging, intracranial bleeding, cerebral concussion, and pneumocephaly can be seen with frontal sinus fracture.

\section{Fracture Description}

Frontal sinus fracture can be as an isolated anterior table fracture $(51.8 \%)$, a combination of the anterior and posterior wall fractures $(47.6 \%)$ or an isolated posterior table fracture (0.6 \%) [43] (Fig. 6). Nasofrontal duct injury can also be part of frontal sinus fracture. It is estimated they occur in about $70 \%$ of frontal sinus fracture cases [44].

\section{Indications for Reduction}

Goals for any treatment of frontal sinus fracture are to prevent early and late complications such as sinusitis, mucocele, meningitis, cerebral abscess, and frontal deformity [42]. The treatment choice is based on three main variables: the amount of dislocation, the presence of a cerebrospinal fluid leak, and the nasofrontal outflow system integrity [43]. With isolated anterior table fractures, indications for surgical treatment are mainly cosmetics. Recently, a quantitative amount of dislocation has been analyzed in several studies. The studies indicate that fracture displacement of 4-5 mm or greater should be treated surgically $[43,45 \cdot]$ (Fig. 6). A smaller displacement needs to be evaluated clinically for any esthetic impact and for the presence of nasofrontal duct injury and cerebrospinal fluid leakage, which would justify surgical repair. In posterior table fracture, the treatment goal is to isolate the intracranial contents from the sinus. This is done by cranialization. Indications are presence of cerebrospinal fluid leakage and displaced posterior table for more than one cortex thickness. When the nasofrontal duct is injured or blocked, sinus obliteration needs to be done to prevent sinusitis and mucocele. The evidence is still non-conclusive [46, 47].

\section{Reduction Techniques}

Repositioning the existing bone fragments with titanium plates and screws is one technique for reconstruction of anterior table. In some cases (i.e., delayed intervention, too small bone fragments), camouflage of the defect is more appropriate. Different materials can be used such as titanium mesh and porous polyethylene implant. Coronal approach, existing frontal laceration, open-sky incision (bilateral supraciliary), and endoscopic approaches are different ways to expose the
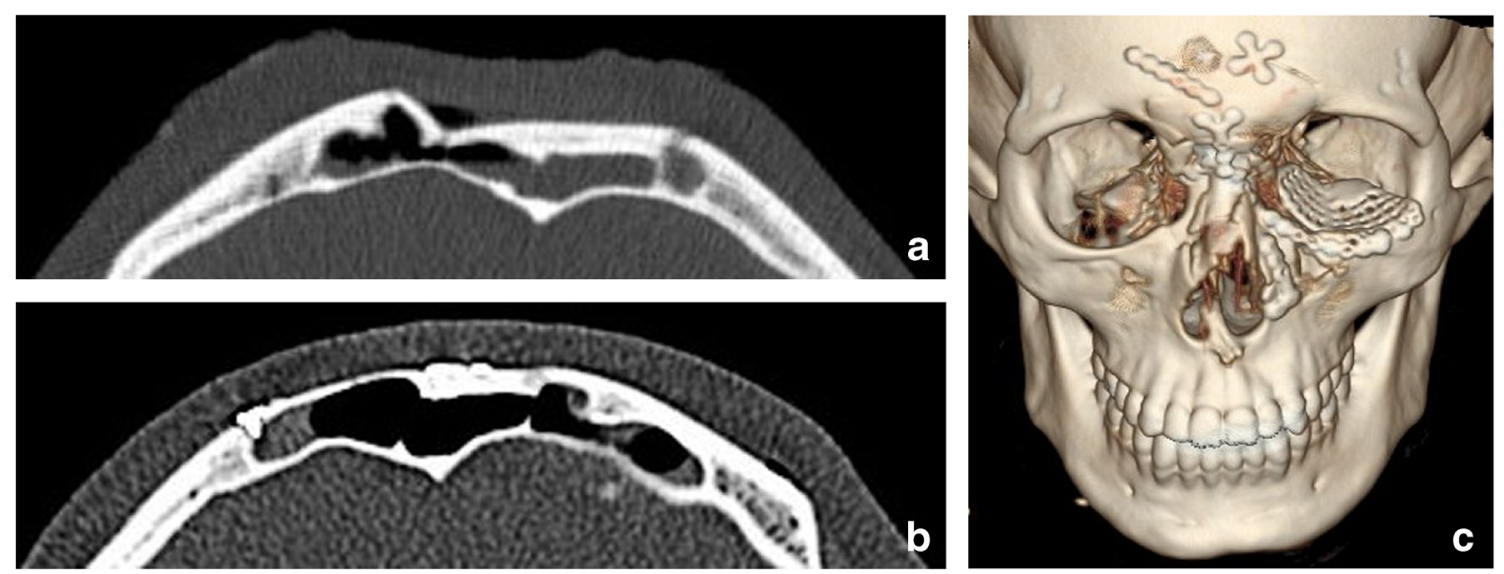

Fig. 6 Frontal sinus fracture. a Axial cut scan showing anterior table fracture with dislocation greater than a cortex. b Post-operative axial cut scan of the same patient after open reduction with internal fixation. $\mathbf{c}$ Post- operative $3 \mathrm{D}$ reconstruction scan of the same patient after open reduction with internal fixation of frontal sinus, bilateral NOE fractures and left orbital floor 
frontal sinus [42]. When addressing the posterior table with cranialization, removal of all the posterior table, curettage of all the sinus mucosa, and obliteration of both nasofrontal ducts needs to be completed. Dural repairs can also be necessary. Different obliteration materials are used such as fat autograft, muscle, pericranium, corticocancellous bone, hydroxyapatite cement, or a combination of these [48].

\section{Panfacial}

Panfacial fractures result from high-energy mechanisms such as motor vehicle collisions and gunshot wounds. There are higher chances of cervical spine and cerebral injuries with these fractures compared to the other facial fractures. The upper, middle, and lower faces need to be involved to be labeled as panfacial fracture [49].

\section{Anatomical Considerations}

The facial skeleton is composed of four vertical and four horizontal buttresses (Fig. 7). These buttresses are thicker bones and define the facial appearance. Anatomical reduction of these landmarks is mandatory to achieve adequate reconstruction in three dimensions especially the projection.

\section{Reconstruction Principles}

The entire face must be approached at the same time. Soft tissue deficit is best managed by secondary reconstruction. Depending on the defect, myocutaneous free flaps, autogenous bone grafts, or alloplastic implants can be indicated in

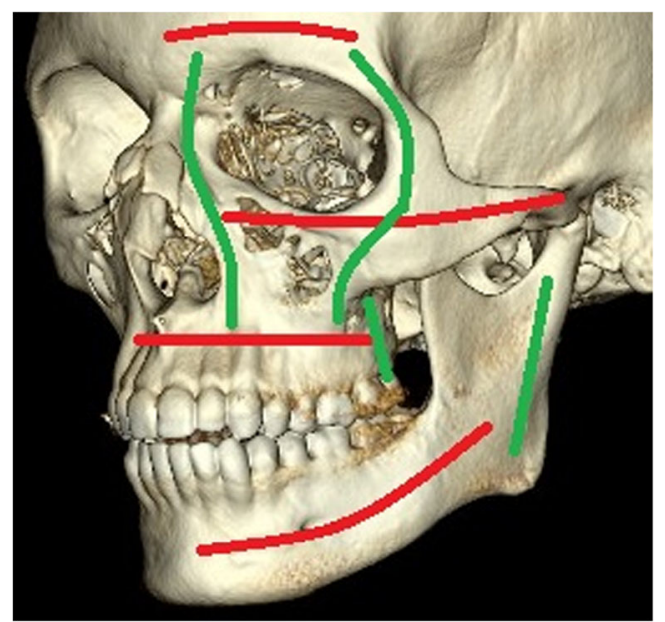

Fig. 7 Representation of facial buttresses. Four horizontal buttresses in red (from top to bottom: frontal, zygomatic, maxillary, mandibular). Four vertical buttresses in green (from lateral to medial: posterior mandibular, pterygomaxillary, zygomaticomaxillary, nasomaxillary) a delayed reconstruction. Different treatment algorithms exist to restore the facial skeleton using the different facial buttresses as landmarks. Reconstruction can be done in a "bottom up" (mandible to frontal bone) or "top down" (frontal bone to mandible) approach, unit by unit (frontal bar, ZMC, NOE complex, maxilla, dentoalveolar complex, mandible) [50-53]. The occlusion gives a reference for the width and the vertical and horizontal planes. Starting from a stable area to an unstable one is advocated.

\section{Pediatric Facial Fractures}

\section{Epidemiology}

Pediatric facial fractures are relatively uncommon. In the USA, pediatric patients make up to $15 \%$ of all facial fractures $[54,55]$. Facial traumas represent about $11 \%$ of pediatric emergency department visits (most of which are dentoalveolar and soft tissue injuries) [56]. The 15- and 17-year-olds are the most frequently injured pediatric group, and only $5 \%$ of all pediatric facial trauma patient are 5 years old or younger [54]. Mandibular, nasal, and maxillary/zygoma fractures are the most frequent each corresponding to about a third of the pediatric facial fractures [57]. These kinds of fractures are mostly associated with high-energy injuries to overcome the bone elasticity. Etiologies of these fractures are greatly influenced by the socioeconomic environment of the child. In recent years, the more frequent mechanisms of injuries are assault, fall, and motor vehicle accident $[57,58]$. As the child grows, sports and bicycling accident become more common [55]. Concomitant injuries such as intracranial hemorrhage, skull, long bones, and pelvic or cervical spine fractures are frequently associated with pediatric facial fractures because of the high-energy mechanisms [59].

\section{Anatomical Considerations}

The first difference between children and adults is in their body mass. Children have a smaller body mass compared to adults; therefore, they receive a greater force per unit of body area and subsequently suffer from more severe injuries compared to adults [60].

The second consideration is their skeleton. Skull fractures are more frequent than maxillofacial fracture in younger children because their cranium is more prominent than the face leading to more number of cranial and neurologic injuries [55]. It is believed that the elasticity of their mandible results in more frequent dentoalveolar fractures than mandibular fractures. Their soft bone makes them less prone to fracture compared to the adult population. Finally, because of their incompletely calcified skeleton, internal organs are more at risk of injuries [60]. 
A third consideration is the dental anatomy. In deciduous dentition, primary teeth offer less retention for wires and splints making fixation more difficult. In mixed dentition, permanent tooth buds occupy most of the alveolar bone leaving less room for internal fixation with plates and screws. Teeth can be missing in the dental arch or loose [60]. On a positive aspect, with growth and tooth exfoliation, spontaneous occlusal readjustment can be seen [61].

The final difference between these two populations is paranasal sinus anatomy. Gradual paranasal sinus pneumatizations start around 5 years of age for the maxillary sinuses and 8 years of age for the frontal sinuses. Full sizes are only reached in young adulthood. This aspect also plays a role in the decrease frequency of facial fracture in the pediatric population [62].

\section{Growth and Developmental Considerations}

Disruption of facial growth can lead to long-term facial deformity after severe midface trauma [63•]. At 5 years of age, the orbits reach about $90 \%$ of their adult size and the cranium reaches approximately $85 \%$ of his mature size. Midface growth vectors are in a vertical and anterior direction and it occurs after the upper third of the face [62]. In the late teenage years, the midface and mandible become more prominent and their growth nears completion. At that time, an increase in facial fractures is observed. Finally, these patients have a greater osteogenic potential and faster healing rate than adults that influences significantly how they are treated [61].

\section{Reduction Considerations}

Because of their fast healing capacity, facial fractures need to be addressed rapidly in children. If reduction is necessary, it should be done within the first few days after injury [64]. Different problems exist with internal fixation in growing children. Multiple factors can disturb the normal facial growth pattern such as scar tissues secondary to the approach, growth plate disturbance by fixation materials, instrumentation, and trauma to the tooth buds. Resorbable plates and screws can be used in the growing patient to prevent growth disturbance. If conventional hardware is used, it should be remove 23 months after fixation. They should not be placed over suture lines [61].

Mandibular nondisplaced fractures can be treated conservatively by observation and soft diet especially in the deciduous and mixed dentition patients. When reduction is needed in cases of displaced fractures, it can be achieved with a closed or an open approach. Factors influencing the approach choice are the age of the patient, the presence of tooth buds, and the condition of teeth present in mouth. Plates and screws can also be palpable in children due to their thin soft tissue. They are
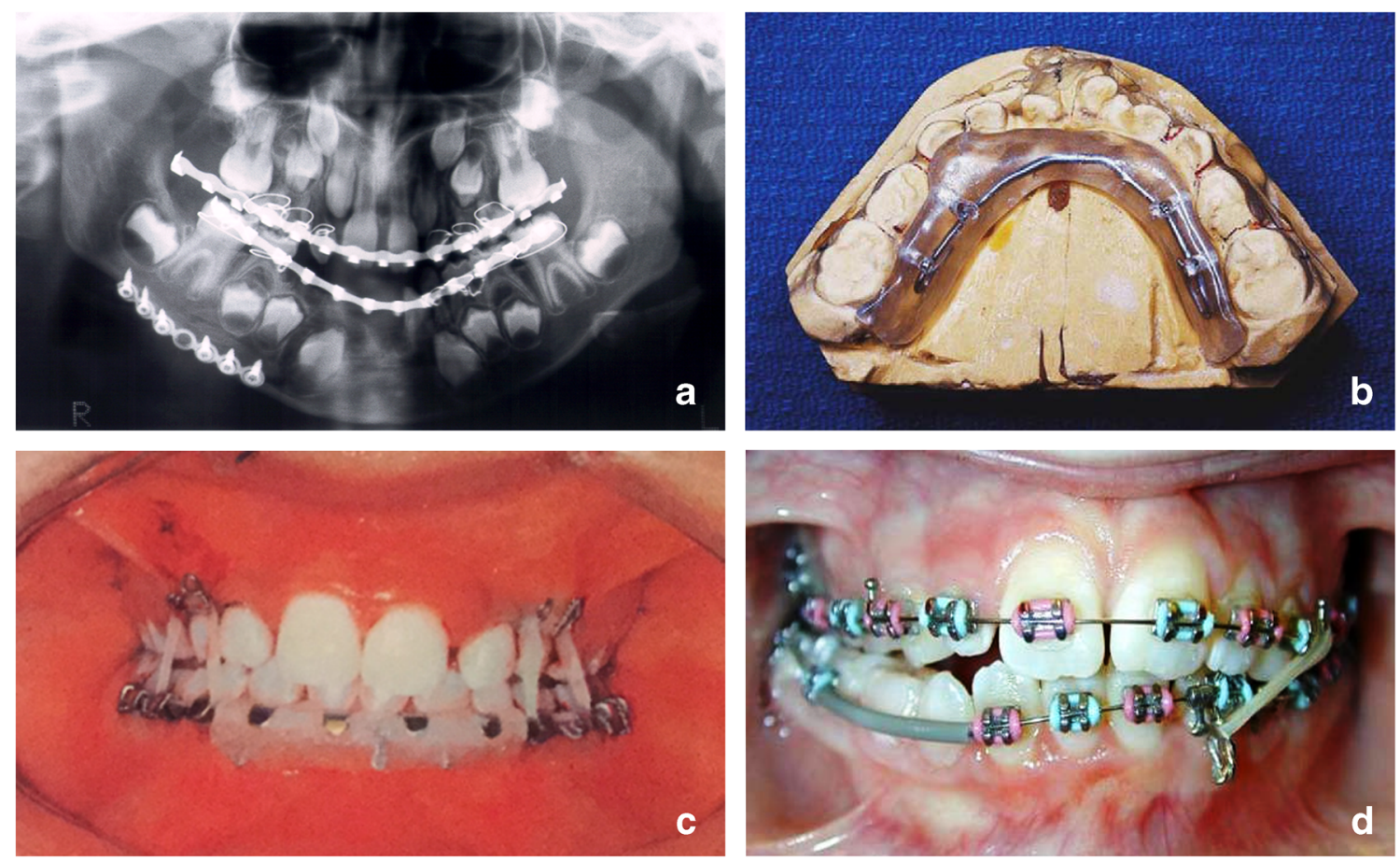

Fig. 8 Different types of fixation used in the pediatric population for mandibular fracture. a Arch bars with inferior border titanium plate. b Lingual splint. c Arch bar and Ivy loops. d Bonded orthodontic

appliances and guiding elastics. (Baumann et al. pp. 450-453, 456; reproduction with permission from Saunders [65]) 
also at greater risk of hardware migration. For all these reasons, in deciduous and mixed dentition, closed reduction is often preferred. In some cases, closed reduction is best achieved with Ivy loops and acrylic splints. If open reduction is necessary, a combination of arch stabilization and one plate fixation at the inferior border away from any tooth bud is the treatment of choice (Fig. 8). Three months after reduction, plate and screws need to be removed. In permanent dentition, they can be treated as adult.

Specific management for orbital fractures is necessary. Because the neurocranium may be still growing, a nondisplaced orbital roof fracture may need reduction and stabilization if the orbit is slowly growing with time. Encephalocele and globe protrusion can be seen. Trap-door orbital floor fracture is more frequent in children than adult. In this kind of fracture, emergent reduction (within $24 \mathrm{~h}$ ) is mandatory to limit muscle ischemia [64].

\section{Conclusions}

Acute management of facial fractures must be based on prompt and thorough evaluation. No real-time frame exists concerning the best moment for facial reconstruction. In few cases such as orbital trapdoor fracture and such as situation where the airway is compromised, early acute management is mandatory. Appropriate management of facial fractures is driven by reconstitution of premorbid facial appearance and occlusion.

\section{Compliance with Ethical Standards}

Conflict of Interest Drs. Chouinard, Troulis, and Lahey declare no conflicts of interest.

Human and Animal Rights and Informed Consent This article does not contain any studies with human or animal subjects performed by any of the authors.

\section{References}

Papers of particular interest, published recently, have been highlighted as:

- Of importance

1. Motamedi MH, Dadgar E, Ebrahimi A, Shirani G, Haghighat A, Jamalpour MR. Pattern of maxillofacial fractures: a 5-year analysis of 8,818 patients. J Trauma Acute Care Surg. 2014;77:630 4.

2. Boffano P, Kommers SC, Karagozoglu KH, Forouzanfar T. Aetiology of maxillofacial fractures: a review of published studies during the last 30 years. Br J Oral Maxillofac Surg. 2014;52:901-6.
3. VandeGriend ZP, Hashemi A, Shkoukani M. Changing trends in adult facial trauma epidemiology. J Craniofac Surg. 2015;26:108-12.

4. Beogo R, Dakoure P, Savadogo LB, Coulibaly AT, Ouoba K. Associated injuries in patients with facial fractures: a review of 604 patients. Pan Afr Med J. 2013;16:119.

5. Kaul RP, Sagar S, Singhal M, Kumar A, Jaipuria J, Misra M. Burden of maxillofacial trauma at level 1 trauma center. Craniomaxillofac Trauma Reconstr. 2014;7:126-30.

6. Scherbaum Eidt JM, De Conto F, De Bortoli MM, Engelmann JL, Dalamaria RF. Associated injuries in patients with maxillofacial trauma at the hospital Sao Vicente de Paulo, Passo Fundo, Brazil. J Oral Maxillofac Res. 2013;4:e1.

7. Mukherjee K, Abhinav K, Revington PJ. A review of cervical spine injury associated with maxillofacial trauma at a UK tertiary referral centre. Ann R Coll Surg Engl. 2015;97:66-72.

8. Alvi A, Doherty T, Lewen G. Facial fractures and concomitant injuries in trauma patients. Laryngoscope. 2003;113:102-6.

9. Mullingan RP, Mahabir RC. The prevalence of cervical spine injury, head injury, or both with isolated and multiple craniomaxillofacial fractures. Plast Reconstr Surg. 2010;126: 1647-51.

10. Gelesko S, Markiewicz MR, Bell RB. Responsible and prudent imaging in the diagnosis and management of facial fractures. Oral Maxillofacial Surg Clin North Am. 2013;25:545-60.

11. Chole RA, Yee J. Antibiotic prophylaxis for facial fractures a prospective, randomized clinical trial. Arch Otolayngol Head Neck Surg. 1987;113:1055-7.

12. Mundinger GS, Borsuk DE, Okhah Z, Christy MR, Bojovic B, Dorafshar $\mathrm{AH}$, et al. Antibiotics and facial fractures: evidencebased recommendations compared with experience-based practice. Craniomaxillofac Trauma Reconstr. 2015;5:64-78. Latest recommendations on antibiotics regimen for facial trauma.

13. Abubaker AO. Use of prophylactic antibiotics in preventing infection of traumatic injuries. Oral Maxillofacial Surg Clin North Am. 2009;21:259-64.

14. Andreasen JO, Jensen SS, Schwartz O, Hillerup Y. A systematic review of prophylactic antibiotics in the surgical treatment of maxillofacial fractures. J Oral Maxillofac Surg. 2006;64:1664-8.

15. Mottini M, Wolf R, Soong PL, Lieger O, Nakahara K, Schaller B. The role of postoperative antibiotics in facial fractures: comparing the efficacy of a 1-day versus a prolonged regimen. J Trauma Acute Care Surg. 2014;76:720-4.

16. Abubaker AO, Rollert MK. Postoperative antibiotic prophylaxis in mandibular fractures: a preliminary randomized, double-blind, and placebo-controlled clinical study. J Oral Maxillofac Surg. 2001;59: 1415-9.

17. Lauder A, Jalisi S, Spiegel J, Stram J, Devaiah A. Antibiotic prophylaxis in the management of complex midface and frontal sinus trauma. Laryngoscope. 2010;120:1940-5.

18. Miles BA, Potter JK, Ellis 3rd E. The efficacy of postoperative antibiotic regimens in the open treatment of mandibular fractures: a prospective randomized trial. J Oral Maxillofac Surg. 2006;64: 576-82.

19. Hurrell MJ, Batstone MD. The effect of treatment timing on the management of facial fractures: a systematic review. Int J Oral Maxillofac Surg. 2014;43:944-50.

20. Hermund NU, Hillerup S, Kodof T, Schwartz O, Andreasen JO. Effect of early or delayed treatment upon healing of mandibular fractures: a systematic literature review. Dent Traumatol. 2008;24: 22-6.

21. Czerwinski M, Parker WL, Correa JA, Williams HB. Effect of treatment delay on mandibular fracture infection rate. Plast Reconstr Surg. 2008;122:881-5. 
22. Marinho RO, Freire-Maia B. Management of fractures of the zygomaticomaxillary complex. Oral Maxillofac Surg Clin North Am. 2013;25:617-36.

23. Deangelis AF, Barrowman RA, Harrod R, Nastri AL. Review article: maxillofacial emergencies: maxillofacial trauma. Emerg Med Australas. 2014;26:530-7.

24. Ogundare BO, Bonnick A, Bayley N. Pattern of mandibular fractures in an urban major trauma center. J Oral Maxillofac Surg. 2003;61:713-8.

25. Morris C, Bebeau NP, Brockhoff H, Tandon R, Tiwana P. Mandibular fractures: an analysis of the epidemiology and patterns of injury in 4,143 fractures. J Oral Maxillofac Surg. 2015;73: 951.e1-951.e12.

26. Ellis E. Condylar process fractures of the mandible. Facial Plast Surg. 2000;16:193-205.

27. Zide MF, Kent JN. Indications for open reduction of mandibular condyle fractures. J Oral Maxillofac Surg. 1983;41:89-98.

28. Troulis MJ, Kaban LB. Endoscopic approach to the ramus/condyle unit: clinical applications. J Oral Maxillofac Surg. 2001;59:503-9.

29. Troulis MJ. Endoscopic open reduction and internal rigid fixation of subcondylar fractures. J Oral Maxillofac Surg. 2004;62:126971.

30. Kellman RM, Cienfuegos R. Endoscopic approaches to subcondylar fractures of the mandible. Facial Plast Surg. 2009;25:23-8.

31. Hackenberg B, Lee C, Caterson EJ. Management of subcondylar mandible fractures in the adult patient. J Craniofac Surg. 2014;25: 166-71.

32. Burnstine MA. Clinical recommendations for repair of isolated orbital floor fractures. An evidence-based analysis. Ophthalmology. 2002;109:1207-10.

33. Gart MS, Gosain AK. Evidence-based medicine: orbital floor fractures. Plast Reconstr Surg. 2014;134:1345-55. Good literature review of orbital floor fractures.

34. Lee JW, Chiu HY. Quantitative computed tomography for evaluation of orbital volume change in blow-out fractures. J Formos Med Assoc. 1993;92:349-55.

35. Chen CT, Chen YR. Endoscopically assisted repair of orbital floor fractures. Plast Reconstr Surg. 2001;108:2011-8.

36. Cheung K, Voineskos SH, Avram R, Sommer DD. A systematic review of the endoscopic management of orbital floor fractures. JAMA Facial Plast Surg. 2013;15:126-30.

37. Avashia YJ, Sastry A, Fan KL, Mir HS, Thaller SR. Materials used for reconstruction after orbital floor fracture. J Craniofac Surg. 2012;23 Suppl 1:1991-7.

38. Ellis E, Kittidumkerng W. Analysis of treatment for isolated zygomaticomaxillary complex fractures. J Oral Maxillofac Surg. 1996;54:386-400

39. Mast G, Ehrenfeld M, Cornelius CP, Tasman AJ, Litschel R. Maxillofacial fractures: midface and internal orbit - part II: principles and surgical treatment. Facial Plast Surg. 2015;31:357-67.

40. Staffel JG. Optimizing treatment of nasal fractures. Laryngoscope. 2002;112:1709-19.

41. Al-Moraissi EA, Ellis E. Local versus general anesthesia for the management of nasal bone fractures: a systematic review and meta-analysis. J Oral Maxillofac Surg. 2015;73:606-15.

42. Guy WM, Brissett AE. Cotemporary management of traumatic fractures of the frontal sinus. Otolaryngol Clin N Am. 2013;46: 733-48.

43. Dalla Torre D, Burtscher D, Kloss-Brandstatter A, Rasse M, Kloss F. Management of frontal sinus fractures - treatment decision based on metric dislocation extent. J Cranio Maxillofac Surg. 2014;42: 1515-9.

44. Fox PM, Garza R, Dusch M, Hwang PH, Girod S. Management of frontal sinus fractures: treatment modality changes at a level 1 trauma center. J Craniofac Surg. 2014;25:2038-42.
45. Kim DW, Yoon ES, Lee BI, Dhong ES, Park SH. Fracture depth and delayed contour deformity in frontal sinus anterior wall fracture. J Craniofac Surg. 2012;23:991-4. This articles describes the significant correlation between the fracture depth and the delayed contour deformity. The significant amount of depth is 4 mm.

46. Kellman R, Goyal P. Managing the frontal sinus in the endoscopic age: has the endoscope changed the algorithm? Craniomaxillofac Trauma Reconstr. 2014;7:203-12.

47. Jafari A, Nuyen BA, Salinas CR, Smith AM, DeConde AS. Spontaneous ventilation of the frontal sinus after fractures involving the frontal recess. Am J Otolaryngol. 2015;36:837-42.

48. Murphy J, Jones NS. How I do it frontal sinus obliteration. J Laryngol Otol. 2004;118:637-9.

49. Curtis W, Horswell BB. Panfacial fractures an approach to management. Oral Maxillofacial Surg Clin North Am. 2013;25:649-60.

50. Markowitz BL, Manson PN. Panfacial fractures: organization of treatment. Clin Plast Surg. 1989;16:105-14.

51. Gruss JS, Bubak PJ, Egbert MA. Craniofacial fractures. An algorithm to optimize results. Clin Plast Surg. 1992;19:195-206.

52. Manson P, Clark N, Robertson B, Slezak S, Wheatly M, Vander Kolk C, et al. Subunit principles in midface fractures: the importance of sagittal buttresses, soft-tissue reductions, and sequencing treatment of segmental fractures. Plast Reconstr Surg. 1999;103: 1287-306.

53. Kelly KJ, Manson PN, Vander Kolk CA, Markowitz BL, Dunham CM, Rumley TO, et al. Sequencing LeFort fracture treatment (organization of treatment for a panfacial fracture). J Craniofac Surg. 1990;1:168-78.

54. Vyas RM, Dickinson BP, Wasson KL, Roostaeian J, Bradley JP Pediatric facial fractures: current national incidence, distribution, and health care resource use. J Craniofac Surg. 2008;19:339-49.

55. Kellman RM, Tatum SA. Pediatric craniomaxillofacial trauma. Facial Plast Surg Clin North Am. 2014;22:559-72.

56. Morris C, Kushner GM, Tiwana PS. Facial skeletal trauma in the growing patient. Oral Maxillofac Surg Clin North Am. 2012;24: $351-64$.

57. Imahara SD, Hopper RA, Wang J, Rivara FP, Klein MB. Patterns and outcomes of pediatric facial fractures in the United States: a survey of the national trauma data bank. J Am Coll Surg. 2008;207: $710-6$.

58. Allareddy V, Itty A, Maiorini E, Lee MK, Rampa S, Allareddy V, et al. Emergency department visits with facial fractures among children and adolescents: an analysis of profile and predictors of causes of injuries. J Oral Maxillofac Surg. 2014;72:1756-65.

59. Hoppe IC, Kordahi BA, Paik AM, Lee ES, Granick MS Examination of life-threatening injuries in 431 pediatric facial fractures at a level 1 trauma center. J Craniofac Surg. 2014;25:1825-8.

60. Macwan CS, Deshpande AN. Unfolding the hidden facts of paediatric maxillofacial trauma. J Clin Diagn Res. 2014;8:ze01-2.

61. Zimmermann CE, Troulis MJ, Kaban LB. Pediatric facial fractures: recent advances in prevention, diagnosis and management. Int $\mathrm{J}$ Oral Maxillofac Surg. 2006;35:2-13.

62. Boyette JR. Facial fractures in children. Otolaryngol Clin N Am. 2014;47:747-61.

63. Davidson EH, Schuster L, Rottgers SA, Smith DM, Naran S, Goldstein JA, et al. Severe pediatric midface trauma: a prospective study of growth and development. J Craniofac Surg. 2015;26: 1523-8. This paper demonstrates the unfavorable impact of midface fracture on facial growth.

64. Maqusi S, Morris DE, Patel PK, Dolezal RF, Cohen MN. Complications of pediatric facial fractures. J Craniofac Surg. 2012;23:1023-7.

65. Baumann A, Troulis MJ, Kaban LB. Facial trauma II: dentoalveolar injuries and mandibular fractures. Pediatric Oral and Maxillofacial Surgery. USA: Elsevier Science; 2004. p. 441-60. 